\title{
Hemorrhagic Synovial Cyst in the Cervical Spine: A Case Report and Review of Literature
}

\begin{abstract}
Tae Hyeong Kim, Min Soo Kim, Eun Suk Park, Jun Bum Park, Soon Chan Kwon, In Uk Lyo, Hong Bo Sim
Department of Neurosurgery, Ulsan University Hospital, University of Ulsan College of Medicine, Ulsan, Republic of Korea

Corresponding author: Hong Bo Sim Department of Neurosurgery, Ulsan University Hospital, University of Ulsan College of Medicine, 877, Bangeojinsunwan-doro, Dong-gu, Ulsan 44033, Republic of Korea

Tel: +82-52-250-7139

Fax: $+82-52-250-7138$

E-mail: nssim01@gmail.com

Received: May 2, 2017

Synovial cysts of the cervical spine are rare entities and intra-cystic hemorrhage have been described in a few of these cases. Traumatic or non-traumatic origins of acute bleeding into the cyst cavity resulting in cyst enlargement and epidural compression have been reported. A 74-year-old woman presented with a 1-year history of bilateral leg weakness that has worsened within the recent couple of weeks. The spine magnetic resonance imaging revealed a heterogeneously enhanced mass which has compressed the spinal cord posteriorly at the C7-T1 level. A cervical laminectomy and removal of the mass were performed. Intra operative examination revealed that the mass contained a hematoma. The histology showed a hemorrhagic synovial cyst. The patient's neurological condition slowly improved to stick-assisted gait after the surgical decompression. We present a case of lower cervical (C7-T1) synovial cyst with acute bleeding and sudden increase in the size of the lesion with spinal cord compression as well as a review of literature.
\end{abstract}

Revised: July 3, 2017

Accepted: July 4, 2017
Key Words: Cervical vertebrae; Hemorrhage; Synovial cysts

\section{INTRODUCTION}

Synovial cysts of the spine are cystic formations connected to the facet joint and contain synovial fluid ${ }^{177}$. These cysts are common in the lumbar spine, but are rare in the cervical spine ${ }^{177}$. Most cervical synovial cysts are found incidentally, but may cause radiculopathy or myelopathy due to compression of the spinal cord or nerve roots ${ }^{4}$. Generally, a symptomatic cervical synovial cyst is often associated with degeneration of the facet joints. Therefore, the pathologic mechanism involved in these cases is considered as of non-traumatic origin ${ }^{12)}$. Few reported cases of a prior traumatic event being implicated in cyst enlargement due to acute bleeding into the cyst cavity, resulting in epidural compression.

We report a patient who presented with a hemorrhagic cervical synovial cyst without a definite trauma history that resulted in spinal cord compression. A review of hemorrhagic causes as a possible mechanism for cyst enlargement was also made.

\section{CASE REPORT}

A 74-year-old-woman with a 10-year history of lower back pain presented with a waxing and waning paresthesia and weakness of both legs that has slowly progressed over 1-year. The patient denied any recent traumatic event and the past clinical history was unremarkable, except for hypertension.
The patient is not on any anticoagulation therapy. Initial neurological examination revealed $\mathrm{G} 4 / 5$ muscle power and diminished sensation in both legs. The patient denied any change in bowel or bladder function.

Magnetic resonance imaging (MRI) of the cervical spine revealed a heterogeneously enhanced cystic mass that has compressed the spinal cord posteriorly at the C7-T1 level. The extradural mass showed heterogeneous signal on T2-weighted images (WI) and the wall of the mass showed diffuse enhancement on contrast enhanced T1-WI. It was inseparable from the left C7 lamina and ligamentum flavum and was compressing the left posterolateral aspect of the spinal cord and the exiting left C8 nerve root (Fig. 1).

We performed a total laminectomy of C7-T1 and lateral mass screw insertion using a posterior approach with transpedicular screw insertion at the T1 level. The mass lesion was completely removed. The mass appeared in continuity with the left C7-T1 facet joint and was adherent to the dural sac. It had cystic components with intralesional subacute bleeding (Fig. 2). The histologic examination of the resected mass showed a cyst having thin fibrous wall with synovial lining, consistent with a synovial cyst (Fig. 3). The patient's neurologic symptoms gradually improved over a few weeks after the surgery.

\section{DISCUSSION}

Spinal synovial cyst is defined as an extradural extrusion 

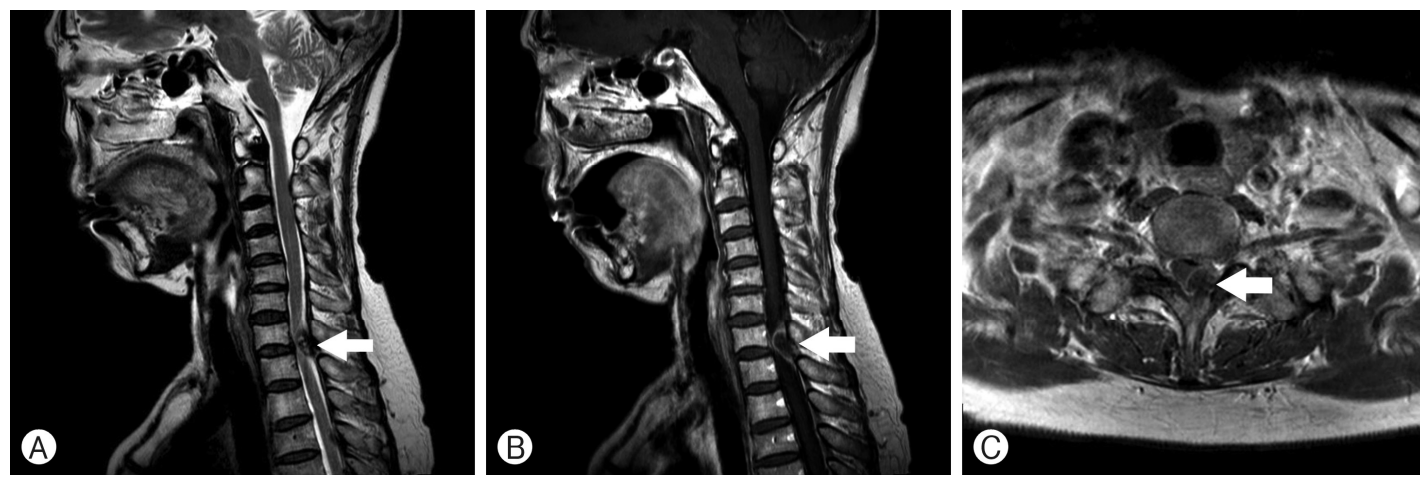

Fig. 1. Magnetic resonance imaging of the cervical spine revealed a heterogeneously enhanced cystic mass compressing the spinal cord posteriorly at the C7-T1 level. The extradural mass showed hete- rogeneous signal on T2-weighted sagittal $(A)$ image and the wall of the mass showed diffuse enhan- cement on contrast enhanced $\mathrm{T} 1$-weighted sagittal (B) and axial (C) images.

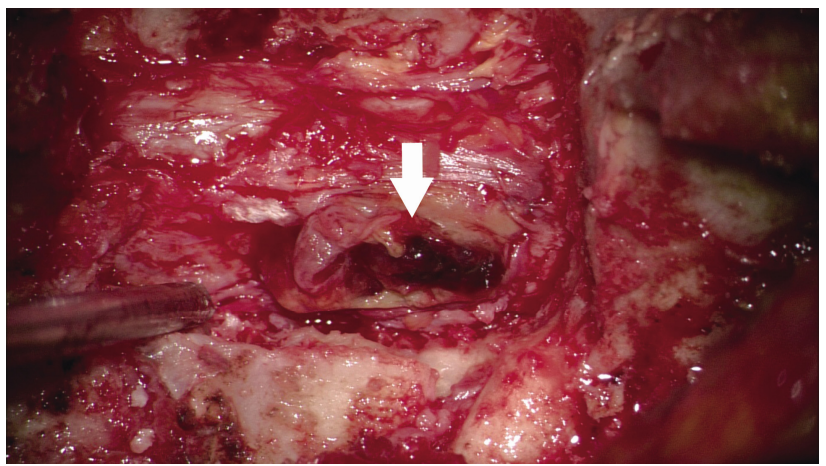

Fig. 2. Intraoperative image showed that the mass was observed to be in continuity with the left C7-T1 facet joint and was adherent to the dural sac. It had cystic components with intralesional subacute bleeding.

of the synovium through a capsular defect from a degenerate or unstable facet joint ${ }^{13)}$. Based on histologic analysis, it is lined internally with a cuboid or pseudostratified columnar epithelium and contains clear fluid ${ }^{10)}$. Since synovial cysts occur most frequently in the lumbar spine, symptomatic cases are much more commonly seen in those affecting the lumbar spine compared with the cervical spine ${ }^{14)}$. The cause of synovial cysts in the cervical spine is multifactorial, but remains uncertain. It is thought that they start with facet joint degenerative change and erosion that extended through the wall of the joint capsule, triggered by hypermobility $^{7,15)}$ or due to a traumatic event ${ }^{15,16)}$. Inflammatory factors may also play an important role in the development of synovial cysts, with upregulation of angiopoeitin-1, basic fibroblastic growth factor, substance P, plateletderived growth factor, and interleukins at the site of the mechanically stressed facet joints contributing to synovial hyperplasia and leading to cyst formation ${ }^{15)}$. Additionally, cervical synovial cysts have most commonly been reported at the cervicothoracic junction, suggesting a predilection for cyst development at a transitional junction between the mobile and fixed segments of the spine ${ }^{15)}$.

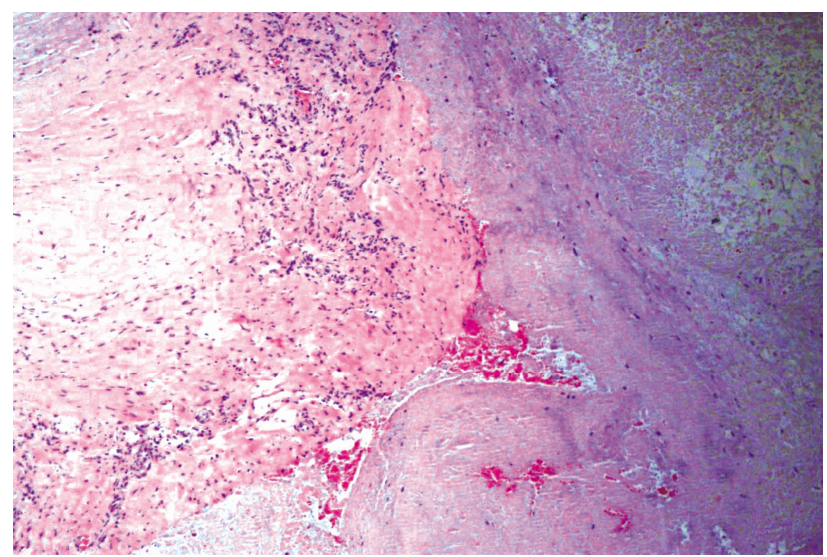

Fig. 3. A photomicrograph of the cyst revealing cystic formation with thin fibrous walls covered by synovial lining (hematoxylin and eosin stain [H \& E], $\times 100$ magnification).

The natural history of symptomatic cervical spine synovial cysts generally follow a slow, stepwise progression of symptoms and signs, all of which commence once there is compression of the spinal cord and/or of the exiting cervical nerve roots. The rapid deterioration of symptoms is thought to be due to hemorrhage into the synovial cysts, where trauma may play a role in the acute expansion". The reason for hemorrhage into a facet cyst is unknown. Theories include increased venular vasculature of the degenerative synovium, as well as degenerative or traumatic rupture of the cyst itself ${ }^{18)}$.

Computed tomography (CT) myelography and MRI are the most useful diagnostic investigations, delineating the synovial cyst arising extradurally next to degenerated facet joints ${ }^{1,3,5)}$. Other useful radiologic findings are the presence of fluid within the cyst, and the extent of cyst compression of the spinal cord and/or of the exiting cervical nerve roots ${ }^{1,11)}$.

Generally, surgery is indicated in the presence of severe pain and neurologic deficits. Some patients recover after surgical removal of the cyst, while others experience spontaneous re- 
solution without surgery ${ }^{2,6}$. In lumbar synovial cysts, CT-guided percutaneous needle aspiration and/or corticosteroid injection have been attempted as non-surgical treatments, but these approaches have not been used to treat cervical synovial cyst ${ }^{8)}$. In cervical synovial cysts, a percutaneous needle procedure may worsen the patient's neurologic symptom because it may cause cyst rupture. Therefore, surgical excision is generally accepted as the treatment of choice for cervical synovial cysts because it results in early neurological improvement without the concern of recurrence ${ }^{12,15)}$.

\section{CONCLUSION}

We present a case of lower cervical (C7-T1) synovial cyst with acute bleeding which lead to a sudden increase in the size of the lesion and spinal cord compression. The relative rarity of spinal synovial cysts and the even more limited number of cervical synovial cysts has led to very few reported cases. Surgery to evacuate the extradural hematoma and to excise the cyst can result in improvement or resolution of the neurological signs and symptoms.

\section{CONFLICTS OF INTEREST}

No potential conflict of interest relevant to this article was reported.

\section{REFERENCES}

1. Apostolaki E, Davies AM, Evans N, Cassar-Pullicino VN: MR imaging of lumbar facet joint synovial cysts. Eur Radiol 10:615623, 2000

2. Colen CB, Rengachary S: Spontaneous resolution of a cervical synovial cyst. Case illustration. J Neurosurg Spine 4:186, 2006

3. Conrad MR, Pitkethly DT: Bilateral synovial cysts creating spinal stenosis: CT diagnosis. J Comput Assist Tomogr 11:196-197, 1987

4. Corredor JA, Quan G: Cervical synovial cyst causing cervical radiculomyelopathy: Case report and review of the literature.
Global Spine J 5:e34-e38, 2015

5. Davis R, Iliya A, Roque C, Pampati M: The advantage of magnetic resonance imaging in diagnosis of a lumbar synovial cyst. Spine (Phila Pa 1976) 15:244-246, 1990

6. Henaux PL, Hamlat A, Riffaud L, Guégan Y, Morandi X: Spontaneous regression of a symptomatic atlanto-occipital joint cyst. Case report. Neurochirurgie 57:129-132, 2011

7. Holtzman RN, Dubin R, Yang WC, Rorat E, Liu HM, Leeds NE: Bilateral symptomatic intraspinal T12-L1 synovial cysts. Surg Neurol 28:225-230, 1987

8. Hsu KY, Zucherman JF, Shea WJ, Jeffrey RA: Lumbar intraspinal synovial and ganglion cysts (facet cysts). Ten-year experience in evaluation and treatment. Spine (Phila Pa 1976) 20:80-89, 1995

9. Jabre A, Shahbabian S, Keller JT: Synovial cyst of the cervical spine. Neurosurgery 20:316-318, 1987

10. Kao CC, Winkler SS, Turner JH: Synovial cyst of spinal facet. Case report. J Neurosurg 41:372-376, 1974

11. Khan AM, Girardi F: Spinal lumbar synovial cysts. Diagnosis and management challenge. Eur Spine J 15:1176-1182, 2006

12. Kim DS, Yang JS, Cho YJ, Kang SH: Acute myelopathy caused by a cervical synovial cyst. J Korean Neurosurg Soc 56:55-57, 2014

13. Kurz LT, Garfin SR, Unger AS, Thorne RP, Rothman RH: Intraspinal synovial cyst causing sciatica. J Bone Joint Surg Am 67: 865-871, 1985

14. Lunardi P, Acqui M, Ricci G, Agrillo A, Ferrante L: Cervical synovial cysts: case report and review of the literature. Eur Spine J 8:232-237, 1999

15. Lyons MK, Birch BD, Krauss WE, Patel NP, Nottmeier EW, Boucher OK: Subaxial cervical synovial cysts: report of 35 histologically confirmed surgically treated cases and review of the literature. Spine (Phila Pa 1976) 36:E1285-E1289, 2011

16. McGuigan C, Stevens J, Gabriel CM: A synovial cyst in the cervical spine causing acute spinal cord compression. Neurology 65:1293, 2005

17. Shima Y, Rothman SL, Yasura K, Takahashi S: Degenerative intraspinal cyst of the cervical spine: case report and literature review. Spine (Phila Pa 1976) 27:E18-E22, 2002

18. Tatter SB, Cosgrove GR: Hemorrhage into a lumbar synovial cyst causing an acute cauda equina syndrome. Case report. J Neurosurg 81:449-452, 1994 